\title{
ANALISA LOKASI, DESAIN PRODUK DAN HARGA PRODUK TERHADAP KEPUTUSAN PEMBELIAN KONSUMEN TOKO EMAS KAUSAR SOLO
}

\author{
Zulva Nur Fadillah, Eny Kustiyah, Sudarwati \\ Jurusan Manajemen Fakultas EkonomiUniversitas Islam Batik Surakarta \\ e-mail : zulvanurfadillah@gmail.com
}

\begin{abstract}
ABSTRACK
Zulva Nur Fadillah. 2015020109. Location Analysis, Product Design And Product Prices On The Consumer Purchase Decision Of Gold Shop Kausar Solo. Essay. Management Study Program (S1). Islamic Batik University of Surakarta. 2019.
\end{abstract}

In facing a free market with a lot of competition and also a dynamic business development, the company must conduct marketing activities that are right on target and change orientation by serving consumers, continuing to issue products and handling competitors. Of course in running this business there is intense competition so that what is done by companies in marketing activities must further improve the product and be directed more precisely to the target by prioritizing service to consumers, because most consumers prefer to prioritize in service and expect an attractive product. So that the business of gold jewelery has very high potential, because it is for investment or savings in people's lives.

This study aims to determine the effect of location, product design, and product prices on purchasing decisions at the Kausar Solo Gold Shop. This research used quantitative descriptive method. This study uses samples of 100 respondents and an infinite population. The results of this study indicate that location variables negatively affect consumer purchasing decisions, while product design variables and product prices have a significant positive effect on consumer purchasing decisions.

\section{Keyword : location, design, price, consumer purchase decision}

\section{PENDAHULUAN}

Dalam mengahadapi pasar bebas dengan adanya persaingan yang banyak dan dinamis, oleh karena itu yang harus dilakukakan perusahaan dengan melakukan adanya perubahan orientasi terhadap melayani konsumen, terus mengeluarkan produk dan menangani pesaing. Tentunya dalam menjalankan bisnis ini adanya persaingan yang ketat maka perusahaan melakukan cara kegiatan pemasaran agar produk tersebut semakin meningkat untuk mengutamakan pelayanan terhadap konsumen, yang berarti sebagian besar konsumen lebih senang jika diutamakan dalam pelayanan dan mengharapkan sebuah produk yang menarik.

Permasalahan yang timbul yaitu keputusan pembelian konsumen toko emas yang dapat dipengaruhi oleh lokasi, desain produk serta harga produk. Lokasi yang biasa digunakan untuk usaha emas adalah pasar tradisional, mall, dan lain-lain. Lokasi yang aman dan strategis sangatlah berpengaruh pada keputusan pembelian konsumen.

Selain lokasi, desain mempengaruh positif pada keputusan pembelian. Karena desain adalah suatu bentuk aspek citra produk perusahaan (Martini, 2015). Untuk usaha perhiasan emas desain sangat mempengaruhi keputusan pembelian konsumen. Paling banyak dikalangan wanita. Oleh karena itu, toko harus melengkapi segala bentuk atau model yang unik dan baik. Jika desain yang 
ditawarkan lebih beragam dan mengikuti tren yang ada dimasyarakat, maka konsumen akan melakukan pembelian kembali.

Selain desain yang berpengaruh terhadap keputusan pembelian konsumen, harga produk pun ikut berpengaruh positifpada toko emas. Menurut kotler dalam martini harga termasuk salah satu bauran pemasaran menghasilkan pendapatan dan biaya menurut unsur lainnya. Jadi harga merupakan penyesuaian dalam bauran pemasaran yang membutuhkan waktu banyak. Bisa dikatakan harga yaitu suatu transaksi seorang penjual dengan konsumen untuk membedakan penawaran dari toko lain. Harga untuk emas selalu mengikuti naik turunnya dollar agar meningkatkan pembelian.

Toko merupakan tempat tertutup dengan adanya kegiatan perdagangan dengan jenis benda atau barang yang khusus. Secara fisik, toko mempunyai kesan mewah dan modern daripada warung. Kelengkapan barang serta proses transaksi menggunakan trend terkini. Misalnya toko buku, toko bangunan, toko perhiasan, dan sebagainya.

Toko Emas Kausar adalah suatu bentuk usaha yang bergerak dibidang industri. Toko Emas Kausar memiliki 2 toko yang bertepatan di Jalan Dr Radjiman kios Pasar Jongke dan memiliki cabang di Jalan Ahmad Yani kios Pasar Kartasura. Toko emas kausar Pasar Jongke mulai berdiri sejak awal bulan pada tahun 1998 dan didaerah Pasar Kartasura pada tahun 2014.

\section{METODOLOGI PENELITIAN}

Metode yang digunakan dalam penelitian ini adalah pendekatan deskriptif kuantitatif. Lokasi penelitian di Toko Emas Kausar Solo. Populasi yang berjumlah tak terhingga dan menggunakan contoh sampel sebanyak 100 responden.

\section{PEMBAHASAN}

\section{Uji Asumsi Klasik}

\section{Hasil Uji Normalitas}

Uji normalitas bertujuan untuk menguji apakah dalam model regresi, variabel terikat dan variabel bebas keduanya mempunyai distribusi normal ataukah tidak. Peneliti menggunakan uji statistik non parametric (Maryam, 2011:63). Hasil uji normalitas dengan menggunakan Kolmogorov - Smirnov test sebagai berikut:

\begin{tabular}{llllll} 
& \multicolumn{5}{c}{ Tabel 1 Hasil Uji Normalitas } \\
\hline Variabel & $\begin{array}{l}\text { Kolmogorov- } \\
\text { Smirnov Test }\end{array}$ & Sign & Probabilitas & Kesimpulan \\
& 0.103 & 0.11 & $>0,05$ & $\begin{array}{c}\text { Data } \\
\text { normal }\end{array}$ & terdistribusi \\
\hline $\begin{array}{l}\text { Asymp. } \\
\text { Sig.(2- }\end{array}$ & & & & & \\
Tailed) & & & & & \\
\hline
\end{tabular}

Hasil pengujian menunjukkan Asymp. Sig. (2-tailed) $(0,11)>0,05$. Artinya menunjukkan bahwa tidak signifikan, berarti Ho di terima artinya data tersebut residual berdistribusi normal. 


\section{Hasil Uji Multikolinearitas}

Tabel 2 Hasil Uji Multikolinearitas

\begin{tabular}{llllll}
\hline $\begin{array}{l}\text { Variabel } \\
\text { Independen }\end{array}$ & Tolerance & Std & VIF & Std & Keterangan \\
\hline Lokasi & 0.663 & $>0.10$ & 1.09 & $<10$ & Tidak Ada Multikolinearitas \\
Desain Produk & 0.584 & $>0.10$ & 1.713 & $<10$ & Tidak Ada Multikolinearitas \\
Harga Produk & 0.738 & $>0.10$ & 1.356 & $<10$ & Tidak Ada Multikolinearitas \\
\hline
\end{tabular}

Berdasarkan tabel 2 menunjukkan tidak terjadi multikolinearitas karena nilai tolerance value $>0,10$ dan nilai VIF < 10. maka dapat disimpulkan bahwa tidak terdapat multikolinearitas.

\section{Hasil Uji Heteroskedastisitas}

Tabel 3 Uji Heteroskedastisitas

\begin{tabular}{ccc}
\hline Model & Sig. & Keterangan \\
\hline Lokasi & .254 & Tidak Ada Heteroskedastisitas \\
Desain Produk & .162 & Tidak Ada Heteroskedastisitas \\
Harga Produk & .820 & Tidak Ada Heteroskedastisitas \\
\hline
\end{tabular}

Hasil perhitungan uji Heteroskedasitas menunjukkan probability value untuk variabel lokasi 0,254 , desain 0,162 , harga 0,820 , p-value $>0,05$ tidak terjadi heteroskedasitas.

\section{Hasil Analisis Data \\ Regresi Linear Berganda}

Nilai a dan b1, b2, b3 dalam uji regresi linear berganda adalah:

\begin{tabular}{lcc}
\multicolumn{3}{c}{ Tabel 4 Analisis Regresi Linear Berganda } \\
\hline Model & \multicolumn{2}{c}{ Unstandardized Coefficients } \\
& $B$ & Std. Error \\
& & 3.033 \\
(Constant) & -8.678 & .182 \\
Store Atmosphere & .308 & .158 \\
Service Excellent & .476 & .123 \\
Celebrity Endorser & .651 & \\
\hline
\end{tabular}

Dapat dirumuskan dengan:

$$
\begin{aligned}
& Y=\boldsymbol{a}+\boldsymbol{b}_{1} \boldsymbol{x}_{1}+\boldsymbol{b}_{2} \boldsymbol{x}_{2}+\boldsymbol{b}_{3} \boldsymbol{x}_{3}+\boldsymbol{e} \\
& \mathrm{Y}=-8.678+0,308 \mathrm{X} 1+0,476 \mathrm{X} 2+0,651 \mathrm{X} 3+\mathrm{e}
\end{aligned}
$$

\section{Uji F}

Hasil dari nilai $F_{\text {hitung }}$ sebagai berikut: 


\begin{tabular}{llll}
\multicolumn{4}{c}{ Tabel 5 Hasil Uji F } \\
\hline Model & $\mathrm{F}$ & Sig. & Keterangan \\
\hline Regression & 33,837 & $.000^{\mathrm{b}}$ & $\mathrm{H}_{1}$ diterima \\
& & & $\mathrm{H}_{\mathrm{o}}$ ditolak \\
Residual & & & \\
Total & & & \\
\hline
\end{tabular}

$F_{\text {hitung }}$ sebesar 33,837> $F_{\text {tabel }}$ dengan tingkat signifikan sebesar 0,000 atau $<0,05$. Dapat disimpulkan bahwa Ho ditolak karena lokasi, desain produk dan harga produk terdapat pengaruh simultan terhadap keputusan pembelian konsumen.

\section{Uji t}

Hasil dari Uji t adalah:

\begin{tabular}{llccc}
\multicolumn{5}{c}{ Tabel 6 Hasil Uji t } \\
\hline Model & B & T & Sig. & Keterangan \\
\hline (constant) & -8.678 & -2.861 & .005 & \\
Lokasi & .308 & 1.694 & .093 & $\mathrm{H}_{2}$ ditolak \\
Desain Produk & & & & $\mathrm{H}_{3}$ diterima \\
& .476 & 3.015 & .003 & \\
Harga Produk & & & & $\mathrm{H}_{4}$ diterima \\
& .651 & 5.304 & .000 & \\
\hline
\end{tabular}

Pada variabel lokasi probability value $0,093<0,05 \mathrm{H}_{2}$ ditolak karena adanya pengaruh signifikan dan positif pada keputusan pembelian konsumen Toko Emas Kausar Solo.

Pada variabel desain produk probability value $0,003<0,05$ maka $\mathrm{H}_{3}$ diterima karena adanya pengaruh signifikan dan positif terhadap keputusan pembelian konsumen Toko Emas Kausar Solo.

Dan pada variabel harga produk probability value $0,000<0,05$ maka Ho diterima adanya pengaruh signifikan dan positif pada keputusan pembelian konsumen Toko Emas Kausar Solo.

\section{Koefisien Determinasi}

Perhitungan dari nilai adjusted $R$ square adalah:

Tabel 7 Hasil Koefisien Determinasi

\begin{tabular}{lll}
\hline$R$ & $R$ Square & Adjusted $R$ Square \\
\hline $.717^{\mathrm{a}}$ & .514 & .499 \\
\hline
\end{tabular}

Nilai adjusted $\mathrm{R}$ square $=0,499$ dapat disimpulkan adanya pengaruh variabel lokasi, desain produk, harga produk terhadap variabel terikat keputusan pembelian Toko Emas Kausar 49,9\% sisanya 50,1\% dipengaruhi oleh faktor lain diluar variabel tersebut. 
Penelitian ini dapat dibuktikan bahwa uji F diterima secara simultan dengan variabel lokasi, desain produk, dan harga produk terhadap keputusan pembelian konsumen. Hasil penelitian uji t variabel lokasi tidak berpengaruh pada variabel terikat yaitu keputusan pembelian dengan hasil probability 0,093 > 0,05. Tidak berpengaruh disebabkan adanya lokasi yang ada di pasar tradisional, area parkir tersebut luas dan nyaman. Maka dari itu konsumen tidak mempermasalahkan lokasi toko.

Berdasarkan penelitian analisis dari uji t menunjukkan variabel desain produk berpengaruh terhadap keputusan pembelian konsumen serta simultan memperoleh hasil probability $0,003<0,05$. Apabila desain produk semakin membaik, maka konsumen akan melakukan pembelian kembali. Selain itu desain dapat menghasilkan daya pikat sendiri agar menarik (Rian Pramono, 2011).

Berdasarkan hasil analisis dari uji t menunjukkan variabel harga produk berpengaruh dan signifikan terhadap keputusan pembelian konsumen Toko Emas Kausar Solo. Didasarkan dengan hasil probability sebesar 0,000<0,05. Menurut levitt et.al (159-160) untuk memperoleh validitas prediktif konsep yang berkaitan adanya harga dan tanggapan pangsa pasar dalam 5 dominan yang berbeda adalah:

a. Berburu harga rendah diluar toko

b. Pembelian produk umum

c. Penarikan harga kembali

d. Perilaku responsive kupon dan penjualan

e. Potongan harga

\section{KESIMPULAN}

a. Lokasi tidak berpengaruh pada keputusan pembelian konsumen Toko Emas Kausar Solo.

b. Desain produk berpengaruh positif dan signifikan pada keputusan pembelian konsumen Toko Emas Kausar Solo.

c. Haga produk bahwa ada pengaruh saecara signifikan terhadap keputusan pembelian konsumen pada Toko Emas Kausar.

\section{Saran}

a. Hendaknya Toko Emas Kausar lebih memperbanyak model desain produk baik dari segi bentuk model barang ataupun dari segi model batu agar konsumen dapat meningkatkan keputusan pembelian konsumen.

b. Sebaiknya Toko Emas Kausar selalu memperhatikan lokasi, karena lokasi tersebut sangatlah memperhatinkan bagi konsumen. Jika lokasi Toko Emas Kausar semakin luas dan strategis, agar dapat menimbulkan rasa kenyamanan terhadap keputusan pembelian konsumen.

c. Dalam masalah harga sebaiknya Toko Emas Kausar selalu mengikuti naik turunnya harga emas, agar konsumen melakukan pembelian ulang.

d. Disarankan untuk penelitian selsanjutnya agar mengembangkan penelitin ini dengan meneliti variabel lain yang lebih luas, yang belum di teliti dalam penelitian ini. 


\section{DAFTAR PUSTAKA}

Levitt Theodore et.al. 2017. Marketing Classics. Yogyakarta: Amara Books

Martini. 2015. Analisis Pengaruh Harga, Kualitas Produk dan Desain terhadap Keputusan Pembelian Kendaraan Bermotor merek Honda jenis sekuter mattic. Kudus

Maryam, Siti. 2011. Statistik Induktif cetakan pertama. Surakarta. Uniba Press

Pramono. N.Y. 2011. Analisis Pengaruh Harga Kompetitif, Desain Produk, dan Layauan Purna Jual terhadap Keputusan Pembelian Sepeda Motor Yamaha (Studi kasus pada masyarakat kota Semarang). In Undergraduate Thesis. Semarang. Universitas Diponegoro 